This item was submitted to Loughborough's Institutional Repository (https://dspace.lboro.ac.uk/) by the author and is made available under the following Creative Commons Licence conditions.

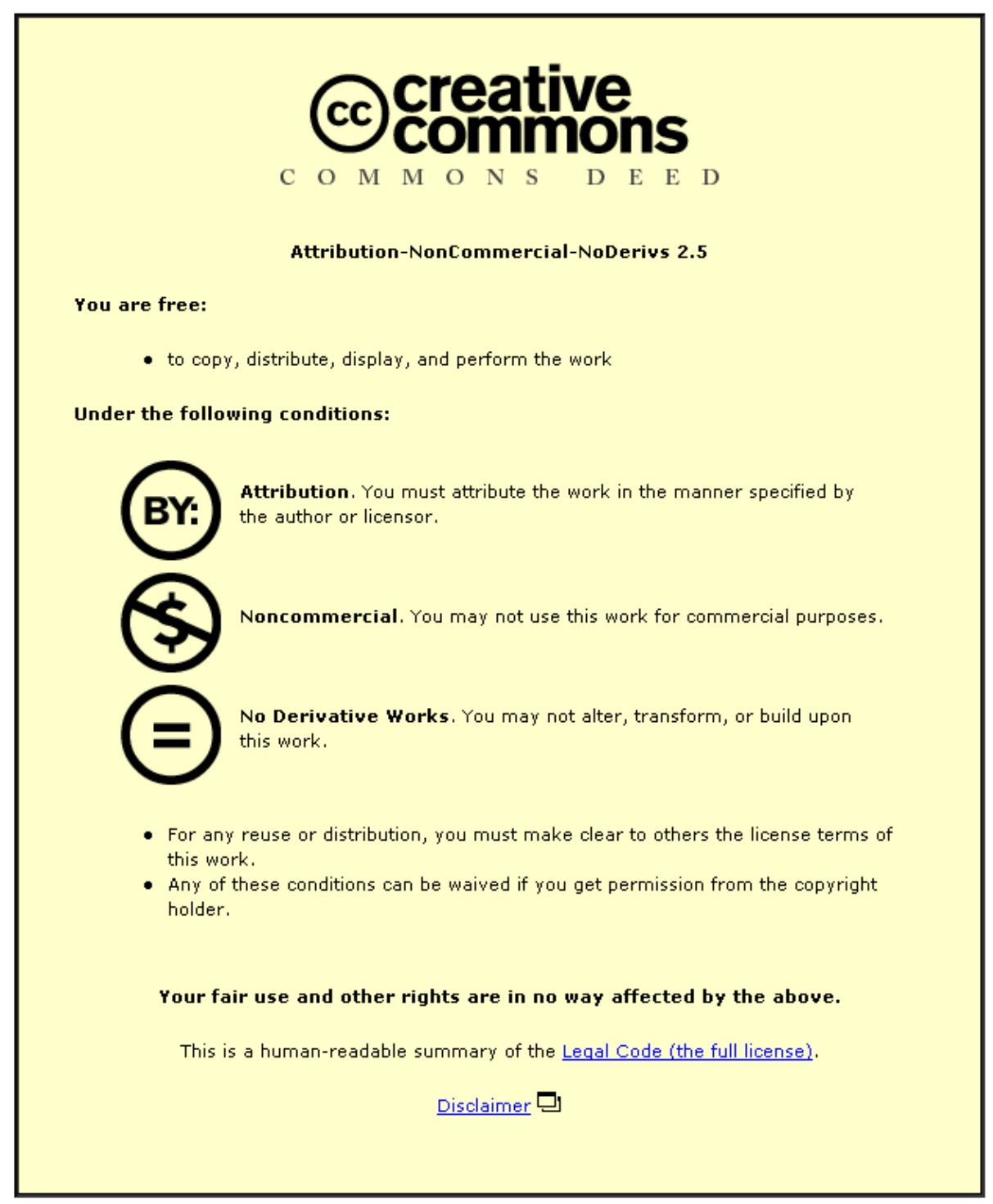

For the full text of this licence, please go to: http://creativecommons.org/licenses/by-nc-nd/2.5/ 


\title{
Cross-linking of unplasticised poly(vinyl chloride) with peroxide
}

\author{
N. L. Thomas*, M. Gilbert and T. Hoang
}

The peroxide cross-linking of poly(vinyl chloride) (PVC) with trimethylolpropane trimethacrylate (TMPTMA) has been investigated. The degree of cross-linking was measured in terms of the gel content of the material, i.e. the insoluble residue remaining after soxhlet extraction in tetrahydrofuran. Cross-linking gave rise to significant improvements in high temperature tensile strength, but at higher levels of peroxide, dehydrochlorination of PVC was found to compete with grafting and cross-linking reactions. The results have been analysed to predict the optimum amount of TMPTMA and peroxide to maximise gel content and strength while maintaining thermal stability.

Keywords: Poly(vinyl chloride), Cross-linking, Peroxide, TMPTMA

\section{Introduction}

Chemical cross-linking of plasticised poly(vinyl chloride) (PVC) has been used as a means of improving mechanical properties at elevated temperatures. ${ }^{1,2}$ The two methods that have been studied are the use of silanes ${ }^{3-8}$ and, to a lesser extent, the use of peroxides. ${ }^{9,10}$ Both methods can successfully produce cross-linked morphologies. The key to success is to produce compounds with adequate crosslinked density while maintaining thermal stability and avoiding premature reaction during processing.

In unplasticised (rigid) PVC, it is more difficult to achieve an optimum combination of properties through chemical cross-linking. Kelnar and Schatz ${ }^{11,12}$ have studied the cross-linking of rigid PVC using mercaptosilane and reported a high cross-linked density when basic lead salts were used as thermal stabilisers. However, cross-linking of rigid PVC was found to be much slower than plasticised PVC. This is owing to the reduced diffusion rate of water in rigid $\mathrm{PVC}$, therefore reducing the rate of the silane hydrolysis reaction. Gilbert and Garcia-Quesada ${ }^{13}$ have investigated aminosilane cross-linking of rigid PVC. Although a notable improvement in tensile strength above the glass transition temperature of the cross-linked polymer was found, there was also a significant deterioration in thermal stability, which is attributable to reactive amine groups that provide high grafting efficiency but also abstract $\mathrm{HCl}$ and therefore reduce thermal stability.

Peroxide cross-linking of rigid PVC has been studied by Gilbert and Garcia-Quesada. ${ }^{13,14}$ They added a trifunctional monomer, trimethylolpropane trimethacrylate (TMPTMA) to the PVC. TMPTMA has the formula $\mathrm{CH}_{3} \mathrm{CH}_{2} \mathrm{C}\left(\mathrm{CH}_{2}-\mathrm{O}-\mathrm{CO}-\mathrm{CCH}_{3}=\mathrm{CH}_{2}\right)_{3}$ and is compatible with PVC. Cross-linking is activated at

Institute of Polymer Technology \& Materials Engineering, Loughborough University, Loughborough, Leicestershire, LE11 3TU, UK

*Corresponding author, email N.L.Thomas@ lboro.ac.uk elevated temperature in the presence of peroxide. The TMPTMA undergoes rapid polymerisation followed by grafting on to the PVC chains and subsequent crosslinking. In these studies significant property improvements were found with as little as 0.5 part of peroxide per hundred parts of PVC (phr). Premature cross-linking during processing was largely avoided but thermal stability was found to deteriorate.

The aim of the present work is to investigate further the use of TMPTMA for the peroxide cross-linking of PVC. Experimental design software was used to determine the formulations and processing temperatures for the study. The resulting polymers were characterised in terms of their gel content, thermal stability and tensile strength at elevated temperature. The results have been analysed to predict the optimum formulation and processing conditions to maximise gel content and strength, while maintaining thermal stability.

\section{Experimental}

\section{Formulations and processing}

Table 1 shows the basic formulation used in the present study. The PVC was suspension grade Evipol SH6030 supplied by Ineos Vinyls. This polymer has a $K$ value of 60 , which corresponds to a weight average molecular weight of $\sim 64000$ and is in the lower molecular weight range of commercially available grades. The heat stabiliser was tribasic lead sulphate (TBLS). The relatively high addition level of 7 phr was chosen because from previous studies ${ }^{14}$ it was anticipated that thermal stability might be a problem. The acrylic processing aid, Paraloid K120N, was supplied by Rohm and Haas. The lubricants used were fatty alcohols, Loxiol G52 and G53, from Echem and a poly(ethylene) wax, PE 190, from Hoechst. The trifunctional monomer, TMPTMA, was supplied by Degussa. Two different peroxides supplied by Chemtura Corporation were used. USP 495D is (1,1di-(t-butylperoxy)-3,3,5-trimethyl cyclohexane), incorporating 
Table 1 Formulation ingredients

\begin{tabular}{ll}
\hline Ingredient & Concentration, phr \\
\hline Evipol SH6030 & 100 \\
Tribasic Lead Sulphate & 7 \\
Loxiol G53 & $1 \cdot 2$ \\
Loxiol G52 & $0 \cdot 4$ \\
Hoechst PE 190 & $0 \cdot 2$ \\
Paraloid K120N & $1 \cdot 5$ \\
TMPTMA & According to experimental design \\
USP 495D & According to experimental design \\
USP 333M & According to experimental design \\
\hline
\end{tabular}

$75 \%$ peroxide and the other peroxide is USP $333 \mathrm{M}$ (ethyl 3,3-di-(t-butylperoxy) butyrate), also incorporating $75 \%$ peroxide. These peroxides were chosen because similar peroxides had been used successfully in previous studies. $1,13,14$

The experimental plan for the present study was produced using the ECHIP software package ${ }^{15}$ and is shown in Table 2. A standard quadratic design was chosen with four design variables: pressing temperature $\left(170-200^{\circ} \mathrm{C}\right)$, TMPTMA concentration $(5-15 \mathrm{phr})$, peroxide concentration $(0 \cdot 12-0 \cdot 6 \mathrm{phr})$ and peroxide type (either USP 495D or USP 333M). This gave 16 unique trials, with a number of repeats to check the statistical significance of the results. An additional midpoint trial at a pressing temperature of $185^{\circ} \mathrm{C}$ and TMPTMA concentration of $10 \mathrm{phr}$ but without any peroxide was included for comparison.

The ingredients were weighed and the dry blends were prepared in a laboratory scale Fielder mixer. All components (except liquid peroxides and TMPTMA) were added to the mixer at a temperature of $50^{\circ} \mathrm{C}$ and mixed at $2000 \mathrm{rev} \mathrm{min}^{-1}$. When the temperature reached $80^{\circ} \mathrm{C}$ the peroxide and TMPTMA were added and blending continued until a temperature of $120^{\circ} \mathrm{C}$ was reached. At this point the blend was discharged into the cooling chamber.

Processing of the dry blends was carried out for $5 \mathrm{~min}$ on a twin roll mill, with the roll temperatures set at $140^{\circ} \mathrm{C}$. The sheets produced were compression moulded under a hydraulic pressure of $20 \mathrm{t}$ for $5 \mathrm{~min}$ at the appropriate pressing temperature according to the experimental plan.

Table 2 Experimental design

\begin{tabular}{llrll}
\hline \multicolumn{2}{c}{$\begin{array}{l}\text { Pressing } \\
\text { temperature, }\end{array}$} & $\begin{array}{l}\text { TMPTMA } \\
\text { concentration, } \\
\text { Trial }\end{array}{ }^{\circ}$ C & $\begin{array}{l}\text { Peroxide } \\
\text { concentration, Peroxide } \\
\text { phr }\end{array}$ & type \\
\hline 1 & 170 & 15 & $0 \cdot 12$ & USP 495D \\
2 & 200 & 5 & $0 \cdot 6$ & USP 495D \\
3 & 170 & 10 & $0 \cdot 6$ & USP 495D \\
4 & 185 & 10 & $0 \cdot 36$ & USP 495D \\
5 & 200 & 15 & $0 \cdot 6$ & USP 495D \\
6 & 200 & 5 & $0 \cdot 12$ & USP 495D \\
7 & 170 & 5 & $0 \cdot 12$ & USP 495D \\
8 & 185 & 15 & $0 \cdot 12$ & USP 495D \\
9 & 170 & 5 & $0 \cdot 36$ & USP 495D \\
10 & 185 & 5 & $0 \cdot 12$ & USP 333M \\
11 & 170 & 10 & $0 \cdot 12$ & USP 333M \\
12 & 170 & 5 & $0 \cdot 6$ & USP 333M \\
13 & 200 & 10 & $0 \cdot 6$ & USP 333M \\
14 & 200 & 15 & $0 \cdot 12$ & USP 333M \\
15 & 200 & 5 & $0 \cdot 36$ & USP 333M \\
16 & 170 & 15 & $0 \cdot 6$ & USP 333M \\
\hline & & & &
\end{tabular}

\section{Characterisation and property measurements \\ Gel content}

The amount of cross-linked PVC (or gel content) was determined by Soxhlet extraction for $24 \mathrm{~h}$ using tetrahydrofuran (THF) as a solvent. The THF was removed from the residue by drying the cellulose extraction thimble for $8 \mathrm{~h}$ at $100^{\circ} \mathrm{C}$. The gel content was calculated as the percentage of dried sample remaining after extraction.

\section{Thermal stability}

The thermal stability of the PVC samples was determined using an oven at $190^{\circ} \mathrm{C}$, according to ASTM D2115-67. Small strips of sample were cut and placed in an aluminium foil holder, which was put on an oven tray. Strips were removed from the oven every $10 \mathrm{~min}$ and any changes in colour were observed.

\section{Tensile properties}

Ultimate tensile strength (UTS) was determined at $130^{\circ} \mathrm{C}$ using a Hounsfield tensometer at a strain rate of $50 \mathrm{~mm} \mathrm{~min}{ }^{-1}$. The samples were prepared according to ASTM D638-84. Eight test pieces were used for each test. Testing was carried out at $130^{\circ} \mathrm{C}$ because from previous work this was found to be a suitable temperature for assessing improvements in elevated temperature properties. ${ }^{13}$ Samples were conditioned at this temperature for $20 \mathrm{~min}$ before testing.

\section{Results and discussion}

\section{Gel content}

Results of gel content measurements from the 16 different trials and three repeat formulations are given in Table 3. The gel content of the control sample pressed at $185^{\circ} \mathrm{C}$ and containing $10 \mathrm{phr}$ of TMPTMA but no peroxide was $8 \cdot 5 \%$. This result shows that there is some cross-linking of the TMPTMA under the action of heat even in the absence of peroxide.

Gel content results were fed back into the ECHIP programme to model the effect of the input variables (pressing temperature, TMPTMA concentration, peroxide concentration and peroxide type) on the gel content. Regression analysis was carried out to obtain

Table 3 Experimental results

\begin{tabular}{llll}
\hline Trial & $\begin{array}{l}\text { Gel } \\
\text { content, } \%\end{array}$ & $\begin{array}{l}\text { Time to } \\
\text { degradation, min }\end{array}$ & $\begin{array}{l}\text { Tensile } \\
\text { strength, MPa }\end{array}$ \\
\hline 1 & $25 \cdot 0$ & 30 & $2 \cdot 17$ \\
2 & $35 \cdot 0$ & 30 & $1 \cdot 67$ \\
3 & $30 \cdot 0$ & 30 & $1 \cdot 90$ \\
4 & $40 \cdot 0$ & 30 & $1 \cdot 97$ \\
5 & $25 \cdot 0$ & 30 & $1 \cdot 60$ \\
6 & $13 \cdot 6$ & 30 & $1 \cdot 43$ \\
7 & $13 \cdot 0$ & 30 & $1 \cdot 48$ \\
8 & $30 \cdot 0$ & 30 & $2 \cdot 22$ \\
9 & $18 \cdot 0$ & 30 & $1 \cdot 43$ \\
10 & $26 \cdot 0$ & 20 & $1 \cdot 46$ \\
11 & $25 \cdot 0$ & 30 & $1 \cdot 78$ \\
12 & $26 \cdot 0$ & 20 & $1 \cdot 40$ \\
13 & $33 \cdot 0$ & 10 & $2 \cdot 24$ \\
14 & $28 \cdot 0$ & 20 & $2 \cdot 51$ \\
15 & $31 \cdot 0$ & 30 & $2 \cdot 36$ \\
16 & $39 \cdot 4$ & 10 & $2 \cdot 10$ \\
$1 \mathrm{R}$ & $29 \cdot 4$ & 30 & $2 \cdot 35$ \\
$9 \mathrm{R}$ & $18 \cdot 6$ & 30 & $1 \cdot 33$ \\
$12 \mathrm{R}$ & $23 \cdot 4$ & 20 & $1 \cdot 52$ \\
\hline
\end{tabular}




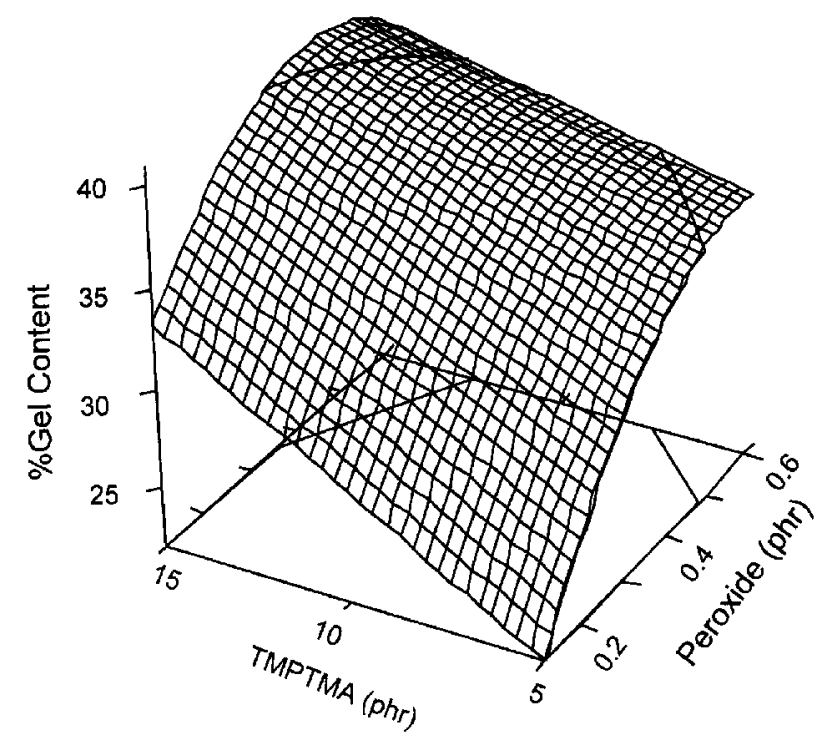

1 3D contour plot of effect of TMPTMA and peroxide concentration on gel content: temperature $=185^{\circ} \mathrm{C}$ and peroxide $=$ USP $495 \mathrm{D}$

the best fit quadratic equation from the data. The equation derived is given below. In this and subsequent equations the terms 'TMPTMA' and 'peroxide' refer to the addition levels of these materials

$\%$ Gel content $=38 \cdot 546+0 \cdot 0158($ Temperature -185$)$

$+0 \cdot 7719($ TMPTMA -10$)+20 \cdot 631($ Peroxide $-0 \cdot 36)$

- 0.0521(Temperature - 185)(TMPTMA - 10)

$-1 \cdot 442$ (TMPTMA - 10)(Peroxide - 0.36)

- 0.03936(Temperature -185$)^{2}-65 \cdot 884$ (Peroxide-

$0 \cdot 36)^{2}-2 \cdot 146($ if USP495D) $+2 \cdot 146($ if USP333M)

As expected, it was found that increasing the concentration of both TMPTMA and peroxide in the formulation gave a significant increase in the gel content. Peroxide USP 333M gave a slightly higher gel content than USP 495D. Pressing temperature was not found to have a significant effect overall.

The relationship is displayed graphically in the contour plot of Fig. 1. This three-dimensional graph shows gel content on the vertical axis plotted against both TMPTMA and peroxide concentration. Gel content can be seen to increase with increasing concentration of both TMPTMA and peroxide but reaches a plateau at a peroxide concentration of $\sim 0.5 \mathrm{phr}$.

These observations can be explained by considering the cross-linking process. It is known ${ }^{16}$ that polymerisation of TMPTMA occurs more readily than grafting on to $\mathrm{PVC}$, therefore, this will be the initial reaction. In their work on irradiation cross-linking of PVC, Bowmer et al. $^{16}$ showed that $30 \%$ of the double bonds in TMPTMA are used during this initial polymerisation. Subsequently the TMPTMA homopolymer grafts on to the PVC to produce a gel, with further double bonds reacting. Increasing TMPTMA concentration would clearly be expected to increase gel content, as reported in previous work by Garcia-Quesada and Gilbert. ${ }^{14}$ In the previous study a plateau in gel content was obtained with $0.5 \mathrm{phr}$ peroxide, but lower concentrations of peroxide were not investigated. In the present study, it is confirmed that gel content is lower with lower peroxide concentrations, and the plateau is still seen at a peroxide concentration of $\sim 0.5 \mathrm{phr}$. This level is therefore necessary; further peroxide is not beneficial, irrespective of TMPTMA concentration. The TMPTMA homopolymer will have pairs of double bonds closely spaced along the polymer chain, and it will be impossible for all of these to react to produce gel because of steric hindrance. ${ }^{17}$ If reaction was possible, it would be expected that the plateau for peroxide concentration would move to higher concentrations as the TMPTMA concentration increased. As this is not observed, it is more likely that excess peroxide causes chain scission as well as gel formation. It is known that chain scission (associated with thermal degradation) can occur during PVC processing, and it is reasonable that this could be enhanced in the presence of excess free radicals and also at higher pressing temperatures.

\section{Thermal stability}

Thermal stability was measured as time to degradation as specified in ASTM D2115-67 based on the change of colour of the PVC samples at $190^{\circ} \mathrm{C}$. The results are shown in Table 3 . It is seen that all samples containing peroxide USP 495D had a thermal stability of $30 \mathrm{~min}$, whereas those containing USP 333M had reduced thermal stability. The control sample (with pressing temperature $185^{\circ} \mathrm{C}$, TMPTMA concentration $10 \mathrm{phr}$ and no peroxide) also had a time to degradation of $30 \mathrm{~min}$.

Regression analysis was carried out on these data using the ECHIP software and the best fit equation was determined to model the effect of the input variables on thermal stability as shown below

Degradation time $(\mathrm{min})=23.62-0.0252($ Temperature 185) - 0.5897(TMPTMA - 10) - 13.618(Peroxide-

$0 \cdot 36)$ - 1.937(TMPTMA - 10)(Peroxide - 0.36)

$$
+4 \cdot 290(\text { if USP495D) }-4 \cdot 290(\text { if USP333M) }
$$

It is found that pressing temperature has no significant effect on thermal stability, whereas increasing the concentration of both TMPTMA and peroxide causes a reduction in thermal stability for reasons discussed earlier. However, the overriding effect is the type of peroxide used: USP $333 \mathrm{M}$ clearly has a deleterious effect on thermal stability compared with USP 495D. USP $333 \mathrm{M}$ has higher active oxygen content $(8 \cdot 2 \%)$ than USP 495D $(7 \cdot 9 \%)$. This could account for both the higher gel content and lower thermal stability of compounds in which USP $333 \mathrm{M}$ is used.

These results are illustrated in the two-dimensional contour plots of Figs. 2 and 3. These graphs show peroxide concentration on the abscissa and TMPTMA concentration on the ordinate. Time to degradation is plotted as a series of contour lines. Peroxide USP 333M (Fig. 3) is shown to give a shorter time to degradation than peroxide USP 495D (Fig. 2).

\section{Tensile strength}

Data obtained for UTS of the samples at $130^{\circ} \mathrm{C}$ are shown in Table 3. The control sample had a UTS of $0.8 \mathrm{MPa}$.

Multiple regression analysis was used to derive the best fit quadratic equation describing the effect of the 


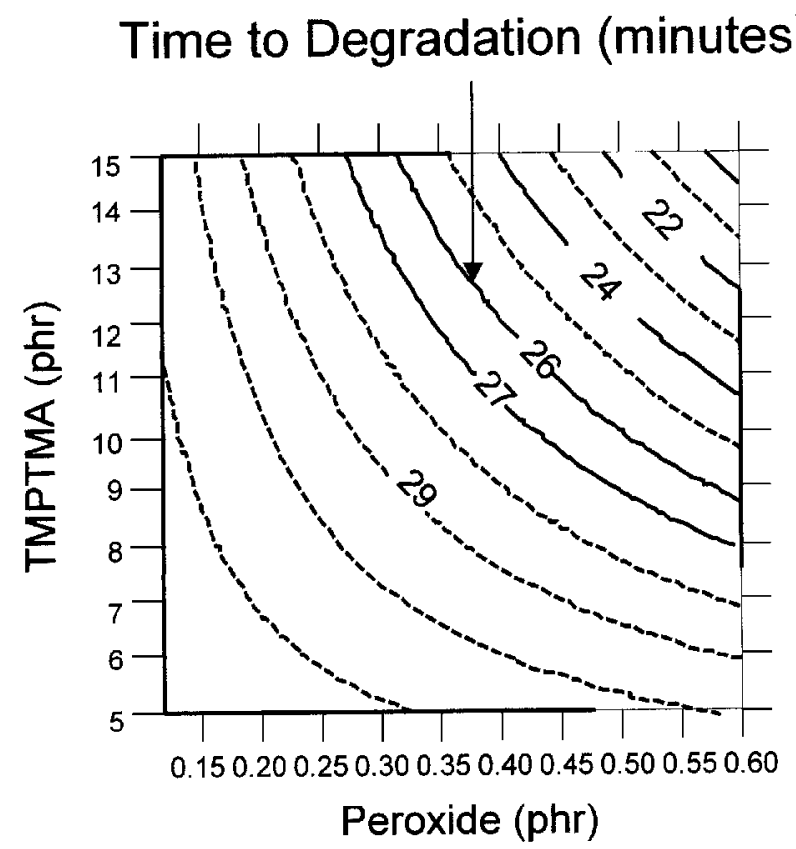

2 2D contour plot of thermal stability: temperature $=$ $185^{\circ} \mathrm{C}$ and peroxide $=$ USP $495 \mathrm{D}$

input variables on UTS at $130^{\circ} \mathrm{C}$ as shown below:

UTS at $130^{\circ} \mathrm{C}(\mathrm{MPa})=2 \cdot 11+0 \cdot 006($ Temperature -185$)$

$+0 \cdot 059($ TMPTMA -10$)-0 \cdot 197($ Peroxide $-0 \cdot 36)$

$-0 \cdot 0019($ Temperature -185$)($ TMPTMA -10$)$

$-0 \cdot 112($ TMPTMA -10$)($ Peroxide $-0 \cdot 36)$

$-4 \cdot 34(\text { Peroxide }-0 \cdot 36)^{2}-0 \cdot 12($ if USP495D)

$+0 \cdot 12($ if USP333M)

From this analysis it is found that the concentration of TMPTMA is the most important variable governing tensile strength at $130^{\circ} \mathrm{C}$. The higher the concentration of

\section{Time to Degradation (minutes)}

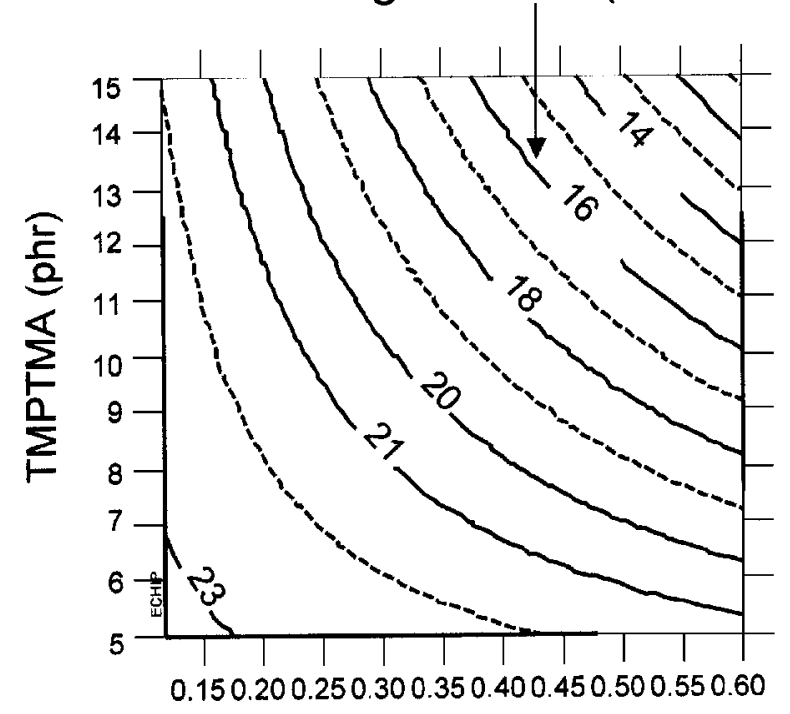

Peroxide (phr)

3 2D contour plot of thermal stability: temperature= $185^{\circ} \mathrm{C}$ and peroxide $=$ USP $333 \mathrm{M}$

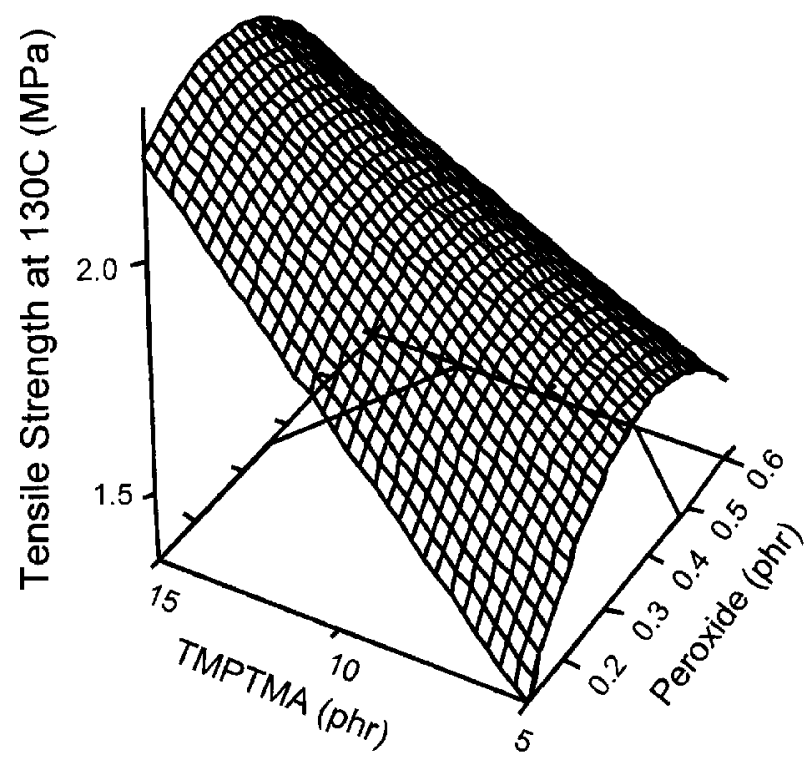

4 3D contour plot of effect of TMPTMA and peroxide concentration on tensile strength at $130^{\circ} \mathrm{C}$ : temperature $=185^{\circ} \mathrm{C}$ and peroxide $=$ USP 495D

TMPTMA, the higher the UTS. Increasing peroxide concentration causes an increase in UTS up to a maximum value. As shown in the $3 \mathrm{D}$ contour plot of Fig. 4, UTS reaches a maximum at intermediate levels of peroxide and then decreases. Peroxide type USP 333M gives higher values of UTS than peroxide type USP 495D.

The effect of pressing temperature on UTS at $130^{\circ} \mathrm{C}$ is rather complex. Although pressing temperature is found to have no overall effect, there is significant interaction between pressing temperature and the TMPTMA concentration. As shown in the 2D contour plot of Fig. 5, at high concentrations of TMPTMA there is no effect of pressing temperature on UTS, whereas at low

\section{Tensile Strength at $130 \mathrm{C}$}

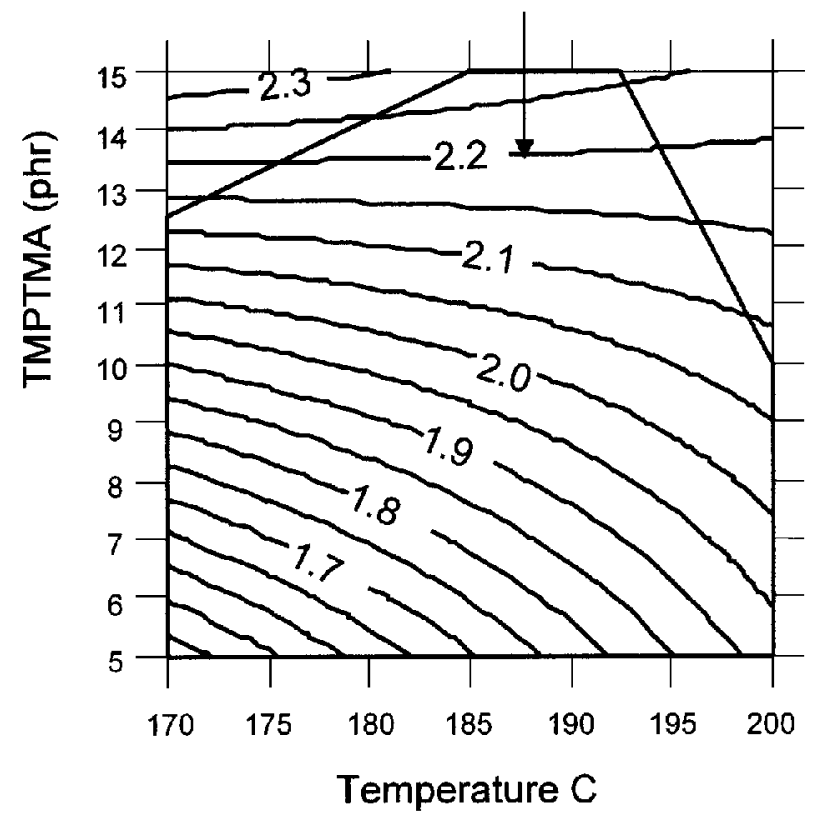

5 2D contour plot of effect of TMPTMA concentration and temperature on tensile strength at $130^{\circ} \mathrm{C}$ : peroxide level $=0.36 \mathrm{phr}$ and peroxide type $=$ USP 495D 
Table 4 Optimum conditions

\begin{tabular}{llll}
\hline $\begin{array}{l}\text { Pressing } \\
\text { temperature, } \\
{ }^{\circ} \mathbf{C}\end{array}$ & $\begin{array}{l}\text { TMPTMA } \\
\text { concentration, } \\
\text { phr }\end{array}$ & $\begin{array}{l}\text { Peroxide } \\
\text { concentration, } \\
\text { phr }\end{array}$ & $\begin{array}{l}\text { Peroxide } \\
\text { type }\end{array}$ \\
\hline $175 \pm 2$ & 15 & $0.27 \pm 0.03$ & USP 495D \\
\hline
\end{tabular}

concentrations of TMPTMA increasing pressing temperature does increase UTS. This possibly relates to melt viscosity before cross-linking occurs; initially TMPTMA will act as a plasticiser, therefore, it will be possible to fuse the PVC effectively at a lower temperature, enabling cross-linking reactions to occur.

A number of observations on these data require further discussion. It is found that increasing the concentration of TMPTMA increases both gel content and UTS. This is expected because more molecules are available for grafting on to the PVC and therefore crosslinking. However, in the case of peroxide, the analysis shows an optimum value of $\sim 0.5 \mathrm{phr}$ at which gel content reaches a plateau. Also in the analysis of the UTS results, there is a distinct maximum at intermediate values of peroxide. Above this value a decrease in high temperature tensile strength is found as shown in Fig. 4. This would be consistent with the occurrence of chain scission as discussed earlier. Another observation is that, as seen in Table 3, there is no significant correlation between gel content and UTS at $130^{\circ} \mathrm{C}$. It is interesting to note that similar observations have been made in previous work by Garcia-Quesada and Gilbert. ${ }^{14}$ This could be explained by chain scission. Although gel content is not increased at higher peroxide levels, neither will it be reduced. However, chain scission in the uncross-linked polymer would cause a reduction in elevated temperature tensile strength.

\section{Optimum conditions}

Analyses of the results of gel content, thermal stability and tensile strength measurements have been combined to predict the set of conditions that will maximise gel content and strength while maintaining thermal stability. The optimum set of conditions is shown in Table 4 . Pressing temperature should be kept to the bottom end of the range to avoid thermal degradation. The optimum value of peroxide is in the middle of the range investigated whereas the optimum value of TMPTMA is the maximum value investigated. Of the two peroxides investigated, type USP 495D is preferable because it gave less reduction in thermal stability.

Inserting these optimum values into the equations derived above, it is found that the predicted gel content is $37 \%$, the time to degradation is $27 \mathrm{~min}$ and the tensile strength at $130^{\circ} \mathrm{C}$ is $2 \cdot 4 \mathrm{MPa}$.

\section{Conclusions}

The present study has examined the peroxide crosslinking of PVC using TMPTMA as the polyfunctional monomer. Experimental design was used to investigate the effects of pressing temperature, the concentration of TMPTMA and the concentration and type of peroxide on gel content, tensile strength and thermal stability of the blends. Using the experimental design approach, it was possible to model the results and therefore map out the effects of a wide range of formulations. Gel yield was found to increase with increasing concentration of TMPTMA but reached a plateau at a peroxide concentration of $\sim 0.5 \mathrm{phr}$. High temperature tensile strength showed significant increase with increasing TMPTMA but reached a maximum value at a peroxide level of $\sim 0.3 \mathrm{phr}$ and then started to fall as peroxide level was increased. This was interpreted as chain scission associated with degradation of PVC. Of the two peroxides investigated, USP 333M (ethyl -3,3-di(t-butylperoxy) butyrate) gave higher gel content but worse thermal stability than USP 495D (1,1-di(t-butylperoxy)-3,3,5-trimethyl cyclohexane). USP $333 \mathrm{M}$ has a higher active oxygen content $(8 \cdot 2 \%)$ than USP 495D $(7 \cdot 9 \%)$ which may account for both the higher gel content and the lower thermal stability of compounds in which USP $333 \mathrm{M}$ was used.

Combining the various analyses it was possible to predict the set of conditions that will maximise gel content and strength while maintaining thermal stability. It is concluded that the optimum conditions are as follows: TMPTMA level of $15 \mathrm{phr}$, peroxide level of $0 \cdot 3 \mathrm{phr}$, peroxide type USP 495D and pressing temperature of $175^{\circ} \mathrm{C}$.

\section{Acknowledgement}

The present work was funded by a Royal Society grant and financial support from Chemtura Corporation, which the authors gratefully acknowledge.

\section{References}

1. M. Gilbert and B. Saethre: Proc. Conf. PVC '96, Brighton, UK, April 1996, The Institute of Materials, 243.

2. J. Pelka and B. Szablowska: Proc. Conf. PVC '96, Brighton, UK, April 1996, The Institute of Materials, 251.

3. J. Pelka and B. Szablowska: Polimery, 1996, 41, 647.

4. M. Hidalgo, L. Gonzalez and C. Mijangos: J. Appl. Polym. Sci., 1996, 61, 1251

5. O. S. Rodriguez-Fernandez and M. Gilbert: J. Appl. Polym. Sci., 1997, 66, 2111

6. J. Sundbo, B. Saethre and S. Pedersen: J. Appl. Polym. Sci., 1998, 67, 849 .

7. M. Hildago, M. I. Beltran, H. Reinecke and C. Mijangos: $\underline{\text { J. Appl. }}$ Polym. Sci., 1998, 70, 865.

8. M. Gilbert and M. Fiaz: Adv. Polym. Technol., 1998, 17, 37.

9. I. G. Yanez-Flores and M. Gilbert: Cell. Polym., 1994, 13, 371.

10. B. Saethre and M. Gilbert: Polymer, 1996, 37, 3379.

11. I. Kelnar and M. Schatz: J. Appl. Polym. Sci., 1993, 48, 657.

12. I. Kelnar and M. Schatz: J. Appl. Polym. Sci., 1993, 48, 669.

13. M. Gilbert and J. C. Garcia-Quesada: Plast., Rubber Compos., 1999, 28, 125.

14. J. C. Garcia-Quesada and M. Gilbert: J. Appl. Polym. Sci., 2000, 77, 2657.

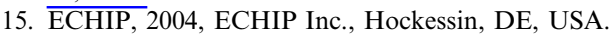

16. T. N. Bowmer, D. D. Davis, T. K. Kwei and W. I. Vroom: J. Appl. Polym. Sci., 1981, 26, 3669.

17. L. P. Nethsinghe and M. Gilbert: Polymer, 1988, 29, 1935. 